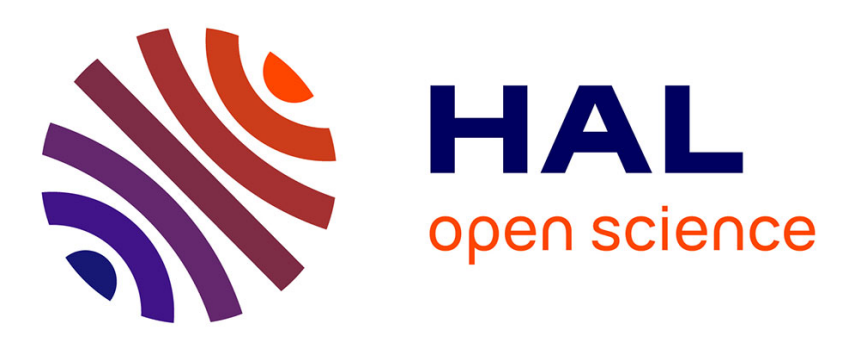

\title{
An example of molecular co-evolution: Reactive oxygen species (ROS) and ROS scavenger levels in Schistosoma mansoni/Biomphalaria glabrata interactions.
}

Yves Moné, Anne-Cécile Ribou, Céline Cosseau, David Duval, André Théron, Guillaume Mitta, Benjamin Gourbal

\section{To cite this version:}

Yves Moné, Anne-Cécile Ribou, Céline Cosseau, David Duval, André Théron, et al.. An example of molecular co-evolution: Reactive oxygen species (ROS) and ROS scavenger levels in Schistosoma mansoni/Biomphalaria glabrata interactions.. International Journal for Parasitology, 2011, 41 (7), pp.721-730. 10.1016/j.ijpara.2011.01.007 . halsde-00580768

\section{HAL Id: halsde-00580768 \\ https://hal.science/halsde-00580768}

Submitted on 29 Mar 2011

HAL is a multi-disciplinary open access archive for the deposit and dissemination of scientific research documents, whether they are published or not. The documents may come from teaching and research institutions in France or abroad, or from public or private research centers.
L'archive ouverte pluridisciplinaire HAL, est destinée au dépôt et à la diffusion de documents scientifiques de niveau recherche, publiés ou non, émanant des établissements d'enseignement et de recherche français ou étrangers, des laboratoires publics ou privés. 
1 An example of molecular co-evolution: reactive oxygen species (ROS) and ROS scavenger

2 levels in Schistosoma mansoni/Biomphalaria glabrata interactions

3

4 Yves Monéa , Anne-Cécile Ribou ${ }^{\mathrm{b}}$, Céline Cosseau ${ }^{\mathrm{a}}$, David Duval ${ }^{\mathrm{a}}$, André Théron ${ }^{\mathrm{a}}$, Guillaume

5 Mitta $^{\mathrm{a}}$, Benjamin Gourbal ${ }^{\mathrm{a}, *}$

6

$7 \quad{ }^{a}$ Parasitologie Fonctionnelle et Evolutive, UMR 5244, CNRS Université de Perpignan, 52 Ave Paul

8 Alduy, 66860 Perpignan Cedex, France

9 b Institut de Modélisation et d'Analyse en Géo-Environnement et Santé (laboratoire IMAGES),

10 EA4218 Université de Perpignan, 52 Ave Paul Alduy, 66860 Perpignan Cedex, France

11

$12 *$ Corresponding author.

13 UMR 5244, CNRS Université de Perpignan, 52 Ave Paul Alduy, 66860 Perpignan Cedex, France.

14 Tel.: +33(0)4 30192312 ; fax: $33(0) 468662281$.

15 E-mail address: benjamin.gourbal@,univ-perp.fr

16

17

18

19

20

21

22 
The co-evolution between hosts and parasites involves huge reciprocal selective pressures on both protagonists. However, relatively few reports have evaluated the impact of these reciprocal pressures on the molecular determinants at the core of the relevant interaction, such as the factors influencing parasitic virulence and host resistance. Here, we address this question in a host-parasite model that allows co-evolution to be monitored in the field: the interaction between the mollusk, Biomphalaria glabrata, and its trematode parasite, Schistosoma mansoni. Reactive oxygen species (ROS) produced by the hemocytes of $B$. glabrata are known to play a crucial role in killing $S$. mansoni. Therefore, the parasite must defend itself against oxidative damage caused by ROS using ROS scavengers in order to survive. In this context, ROS and ROS scavengers are involved in a coevolutionary arms race, and their respective production levels by sympatric host and parasite could be expected to be closely related. Here, we test this hypothesis by comparing host oxidant and parasite antioxidant capabilities between two S. mansoni/B. glabrata populations that have coevolved independently. As expected, our findings show a clear link between the oxidant and antioxidant levels, presumably resulting from sympatric co-evolution. We believe this work provides the first supporting evidence of the Red Queen Hypothesis of reciprocal evolution for functional traits at the field-level in a model involving a host and a eukaryotic parasite.

41 Keywords: Host-parasite co-evolution, Schistosoma mansoni, Biomphalaria glabrata, Reactive oxygen species (ROS), ROS scavengers 


\section{Introduction}

Understanding the co-evolution of host-parasite interactions represents a challenge in evolutionary biology. Parasites cause substantial deleterious effects on their hosts, and therefore represent a major driving force in their evolution (Howard, 1991). Similarly, the host immune defenses represent the major selective pressure driving the evolution of parasites. For parasites to survive and develop in the host they must adapt to the host-defense system or they will die. This parallel co-evolution of host-parasite interactions can be viewed as an arms race in which both the host and the parasite develop mechanisms to circumvent the weapons developed by their opponent. In this context of reciprocal co-evolution, illustrated by Van Valen (1974), under the Red Queen Hypothesis it is assumed that the parasitic genes responsible for infectivity will evolve alongside the host defense genes, resulting in adaptation of the interactions between local host and parasite populations (Dybdahl and Storfer, 2003). To date, however, only a few studies have sought to verify this prediction and convincing experiments have only been reported for models involving viruses, bacteria and unicellular eukaryotes (Lohse et al., 2006; Forde et al., 2008).

Demonstrating co-evolution in an animal host-parasite system is not straightforward and most prior discussions of such processes have been indirect, as in studies describing local adaptation when compatibility is higher between sympatric host-parasite combinations than between allopatric combinations (Gasnier et al., 2000; Gagneux et al., 2006; Munoz-Antoli et al.), or studies that have focused on only one trait of the interaction, such as host resistance (Green et al., 2000) or parasite infectivity (Little et al., 2006). Moreover it is important to take into account that non-co-evolutionary mechanisms could also explain correlations between the traits of interacting species and that the absence of correlated traits is not evidence for an absence of co-evolution (Nuismer et al., 2007, 2010; Yoder and Nuismer, 2010). However we assume that the direct examination of reciprocal selection in both the host and the parasite could provide supporting evidence of co-evolution. 
Two relatively recent studies investigated this reciprocal response more thoroughly. In the

first, reciprocal changes in resistance and infectivity were identified for co-evolving Potamopyrgus snail hosts and their trematode parasites; however, while these changes were identified using prevalence phenotypes, they were not supported by the studied functional markers (Koskella and Lively, 2007). The second report provided experimental support for the reciprocity of adaptation costs, rapid genetic changes and increased genetic diversity during the co-evolution of a multicellular host, the nematode Caenorhabditis elegans, and its pathogenic bacteria, the Grampositive bacterium, Bacillus thuringiensis (Schulte et al., 2010). In both papers, co-evolution was studied using laboratory strains selected by experimental evolutionary approaches, and only the second paper focused on molecular changes induced by the co-evolutionary process. Both papers were based on an "over time" approach in which the evolution of phenotypes was monitored over the course of experimental laboratory generations. Other empirical studies have been based on a "point time" approach in which the pattern of co-variations between host-parasite populations or strains that co-evolved independently were assessed at a single experimental time point (Forde et al., 2004; Morgan et al., 2005).

Here, we investigated the reciprocal evolution of molecular mechanisms directly at the core of the host-parasite interaction in a natural system of co-evolution, by comparing host and parasite populations that have co-evolved independently. As a model, we used the interaction between the trematode, Schistosoma mansoni (responsible for human intestinal schistosomiasis), and its mollusk intermediate host, Biomphalaria glabrata. This interaction is a model of choice for the study of potential co-evolutionary dynamics (Webster and Davies, 2001; Webster et al., 2004; Beltran and Boissier, 2008; Beltran et al., 2008; Bouchut et al., 2008; Roger et al., 2008a; Roger et al., 2008b; Roger et al., 2008c; Steinauer, 2009).

During its intramolluskal stage, the parasite must cope with the snail's immune system. One of the main immune effectors in mollusks are the reactive oxygen species (ROS) produced by hemocytes (the circulating immune cells of snails) (Hahn et al., 2000; de Jong-Brink et al., 2001; 
Hahn et al., 2001b; Mourao et al., 2009b). Previous studies conducted by Hahn and co-workers demonstrated that hydrogen peroxide $\left(\mathrm{H}_{2} \mathrm{O}_{2}\right)$ plays a crucial role in the killing of $S$. mansoni sporocysts (Hahn et al., 2001a, b). Furthermore, hemocytes from S. mansoni-resistant snails were shown to generate significantly more $\mathrm{H}_{2} \mathrm{O}_{2}$ than susceptible snails, perhaps due at least in part to the former having constitutively elevated levels of the mRNA encoding the copper/zinc superoxide dismutase (Cu-ZN SOD) (Goodall et al., 2004; Bender et al., 2005; Bender et al., 2007). To resist ROS-mediated attacks, the S. mansoni larvae produce ROS-detoxifying enzymes (Vermeire et al., 2006; Guillou et al., 2007; Vermeire and Yoshino, 2007; Roger et al., 2008c; Wu et al., 2009), several of which appear to be secreted by sporocysts (Guillou et al., 2007; Wu et al., 2009). Supporting this, a recent report showed that antioxidant enzymes produced by $S$. mansoni sporocysts are directly involved in protecting the pathogen against immune cell-mediated oxidative stress (Mourao et al., 2009b).

In this context, the snail-produced ROS and the parasite-produced ROS scavengers are involved in a co-evolutionary arms race, and we can hypothesize that their production levels will be closely related. Here, we tested this hypothesis by comparing host oxidant and parasite antioxidant abilities for two S. mansoni/B. glabrata strains that have evolved independently, originated from different geographic endemic zones and which are found to display significant differences in compatibility.

\section{Materials and methods}

\subsection{Ethics statement}

Our laboratory has received the permit \# A66040 for experiments on animals from both the French Ministry of agriculture and Fishing and the French Ministry of National Education, Research and Technology. Housing, breeding and animal care of the mice followed the ethical requirements of French government. The experimenter possesses the official certificate for animal experimentation 
120 delivered by both ministries (Décret \# 87-848 du 19 octobre 1987; number of the authorization $121007083)$.

\subsection{Biological materials}

Two strains of S. mansoni were used in this study: a Brazilian strain (SmBRE) and a

glabrata (BgBRE and BgGUA, respectively); and (ii) in hamsters (Mesocricetus auratus), as described previously (Théron et al., 1997).

Miracidia from SmBRE and SmGH2 were hatched from eggs axenically recovered from 60-

Briefly, livers were collected and kept overnight at $4^{\circ} \mathrm{C}$ in sterile saline solution $(\mathrm{NaCl} 150 \mathrm{mM})$

containing an antibiotic/antimycotic mixture (penicillin 100 units $/ \mathrm{ml}$, streptomycin $0.1 \mathrm{mg} / \mathrm{ml}$, amphotericin B $0.25 \mu \mathrm{g} / \mathrm{ml}$; Sigma). The livers were then homogenized and the eggs were filtered out, washed, and transferred to spring water. The miracidia were allowed to hatch out under illumination.

\subsection{Schistosome-snail compatibility: snail exposure, infection rates and intensities}

The compatibilities of the tested snail-schistosome combinations were evaluated by monitoring the infection rates (\% of snails infected) and the intensity of infection (number of mother sporocysts (SpI) developed) among snails individually challenged with different numbers of miracidia. As the miracidial dose increased, a larger fraction of the phenotypic diversity in the parasitic isolate was sampled; thus, dose-response curves are much more informative than single-

142 dose challenges when examining the dynamics of compatibility between two host-parasite combinations (Théron et al., 2008). 
snails were replaced in their original containers until their infection status (presence of SpI) was assessed. For the detection of SpI, the snails were fixed 15 days post-exposure, following previously described methods (Gerard et al., 1995; Moné et al., 2010b). In brief, each snail was relaxed in pond water containing an excess of crystalline menthol for $6 \mathrm{~h}$, the body was removed and fixed in modified Raillet-Henry's solution, exhaustive dissection of the head-foot zone was performed, and the number of SpI present in each snail (readily observable as translucent white bodies within an opaque gray tissue background) was determined.

Dose-response curves were obtained by challenging individual snails (30-40 snails per treatment) with doses of $1,10,20,30$ and 50 miracidia. Compatibility was measured for the two sympatric combinations ( $\mathrm{SmBRE}$ versus $\mathrm{BgBRE}$ and $\mathrm{SmGH} 2$ versus $\mathrm{BgGUA}$ ) and the two allopatric combinations (SmBRE versus $\mathrm{BgGUA}$ and $\mathrm{SmGH} 2$ versus $\mathrm{BgBRE}$ ).

\subsection{Cytotoxicity of $\mathrm{H}_{2} \mathrm{O}_{2}$ on $\mathrm{S}$. mansoni sporocysts}

$\mathrm{H}_{2} \mathrm{O}_{2}$ cytotoxicity was measured using the Roche Cytotoxicity Detection Kit (Roche Diagnostics, Mannheim, Germany), which is based on the measurement of lactate dehydrogenase (LDH) activity released from dead and lysed cells into the supernatant. Four hundred miracidia each of SmBRE and SmGH2 were submitted to in vitro transformation to obtain primary sporocysts (Sp1). Briefly, the miracidia were cultured for $24 \mathrm{~h}$ in sterile Chernin's balanced salt solution (CBSS) (Chernin, 1963), containing an antibiotic/antimycotic mixture (penicillin 100 units/ml, streptomycin $0.1 \mathrm{mg} / \mathrm{ml}$, amphotericin B $0.25 \mu \mathrm{g} / \mathrm{ml}$; Sigma). The sporocysts were then exposed to four different concentrations of $\mathrm{H}_{2} \mathrm{O}_{2}(0,75,150$ and $200 \mu \mathrm{M})$ for $2 \mathrm{~h}$ and cytotoxicity was examined according to the manufacturer's instructions. As a positive control, we measured LDH release from Sp1 that had been lysed with the provided lysis solution (high control, HC); this was taken as $100 \% \mathrm{LDH}$ release. To correct for the background, we measured LDH levels in Sp1-free $\mathrm{H}_{2} \mathrm{O}_{2}$-treated culture medium (substance control, SC). All measured values were assayed in 
171 triplicate. The percentage of specific $\mathrm{H}_{2} \mathrm{O}_{2}$-induced LDH release was determined as: \% cytotoxicity

$172=[($ experimental result $-\mathrm{SC}) /(\mathrm{HC}-\mathrm{SC})] \times 100$.

173

2.5. Effect of $\mathrm{H}_{2} \mathrm{O}_{2}$ on S. mansoni sporocyst mortality

Two independent experiments were conducted in triplicate on 24-well plates containing 20

Sp1 (representing $S m B R E$ or $S m G H 2$ ) per well. The Sp1 were in-vitro transformed as described above (see Materials and methods section 2.2), and exposed to 0, 200, 400, 800 or 1,600 $\mu \mathrm{M}$ of microscope, with the Sp1 considered "dead" when we failed to observe motility and/or the beating of the flame-cell flagella.

\subsection{The total antioxidant capacity of S. mansoni sporocysts}

The cumulative (total) antioxidant capacity of the sporocysts was quantified for the two parasite strains, SmBRE and SmGH2, using an Antioxidant Assay Kit (Sigma). For each test, 2,000 sporocysts were in-vitro transformed as described above. After $24 \mathrm{~h}$, fully transformed sporocysts were recovered by gentle centrifugation $\left(800 \mathrm{~g}, 5 \mathrm{~min}, 4^{\circ} \mathrm{C}\right)$. The samples were then disrupted by sonication (three pulses of $20 \mathrm{~s}$ each) and pelleted by centrifugation $\left(12,000 \mathrm{~g}, 15 \mathrm{~min}, 4^{\circ} \mathrm{C}\right)$, and the antioxidant capacity of each supernatant was determined following the manufacturer's recommendations. The amount of protein in each supernatant was determined using a Bradford protein assay kit and used as a correcting factor. The experiment was performed six times per strain.

\subsection{Reverse Transcription-quantitative PCR (RT-qPCR)}

$R T-q P C R$ analyses were conducted to compare the expression of parasite antioxidant enzymes suspected to play key roles in the detoxification of host-induced oxidative stress. Realtime PCR analyses were performed using a LightCycler 2.0 system (Roche Applied Science) and a 
the manufacturer's protocol. Reverse transcription was performed according to previously described

199 procedures (Guillou et al., 2004). qPCR amplification was performed using $2.5 \mu 1$ of cDNA in a 200 final volume of $10 \mu$ containing $3 \mathrm{mM} \mathrm{MgCl}_{2}, 0.5 \mu \mathrm{M}$ of each primer and $1 \mu \mathrm{l}$ of master mix. The 201 primers were designed using either the LightCycler probe design software or the web-based 202 Primer3 plus interface (http://www.bioinformatics.nl/cgibin/ primer3plus/primer3plus.cgi) and are 203 given in Table 1 . The following Light-Cycler run protocol was used: denaturation at $95^{\circ} \mathrm{C}$ for 10 $204 \mathrm{~min}$, followed by 40 cycles of amplification and quantification at $95^{\circ} \mathrm{C}$ for $10 \mathrm{~s}, 60{ }^{\circ} \mathrm{C}$ for $5 \mathrm{~s}$ and $20572{ }^{\circ} \mathrm{C}$ for $16 \mathrm{~s}$, a melting curve of $60-95^{\circ} \mathrm{C}$ with a heating rate of $0.1{ }^{\circ} \mathrm{C} / \mathrm{s}$ and continuous 206 fluorescence measurement, and then a cooling step to $40^{\circ} \mathrm{C}$. For each reaction, the cycle threshold 207 (Ct) was determined using the "Fit Point Method" of the LightCycler Software, version 3.3. The PCR reactions were performed in duplicate and the mean $\mathrm{Ct}$ value was calculated. For each sample, 209 the expression level of the target gene was normalized with regard to the expression of two 210 constitutively expressed genes (28S rRNA and $\alpha$ tubulin). The expression ratio (R) was calculated 211 according to the formula: $\mathrm{R}=2(\Delta \mathrm{Ct}$ ), where $\Delta \mathrm{Ct}$ represents $\mathrm{Ct}$ (target gene) $-\mathrm{Ct}$ (constitutively 212 expressed gene).

\subsection{ROS detection in single cells}

The cell-permeable fluorescent oxygen probe, 1-pyrenebutyric acid (PBA), can be used for 216 the measurement of free radicals in solution (Oter and Ribou, 2009) and in living cells (Ribou et al., 217 2004; Rharass et al., 2006), with the fluorescence intensity and lifetime of PBA decreasing 218 proportionately to the free-radical concentration. Measurement of the fluorescent lifetime offers 219 many advantages over intensity based measurements when working in vivo, not the least that the 220 measurements are independent of the absolute intensity of emitted light and the fluorophore 221 concentration, thereby avoiding artifacts arising from optical losses. Moreover, these probes do not 222 require a reaction with ROS, are usually stable and the fluorescent lifetime is not modified by probe degradation or variations in its intracellular accumulation. 


\subsubsection{Staining and fixation}

Hemolymph samples were recovered from $\mathrm{BgBRE}$ and $\mathrm{BgGUA}$ snails, and aliquots $(150 \mu \mathrm{l})$

were put in a Sykes-Moore chamber. After $4 \mathrm{~h}$, the adhered hemocytes were rinsed with Hank's $\mu \mathrm{M}$ in $1 \%$ ethanol). The hemocytes were then rinsed three times and placed in HBSS for measurements. For fixation experiments, hemocytes were treated as described above except that 231 after the final rinsing step, the cells were killed by incubation for 10 min in Baker solution (10\% paraformaldehyde in $1 \%$ aqueous calcium chloride). In the latter case, the experiments were performed within $1 \mathrm{~h}$ after cell killing, in order to avoid probe reorganization (Ribou et al., 2004).

\subsubsection{ROS quantification by fluorescent-lifetime measurement of single cells}

The fluorescent decay of single living cells loaded with PBA was recorded using timeresolved microfluorimetry, as previously described (Ribou et al., 2003). Briefly, a laser (nitrogen laser NL100; Stanford Research Systems, USA) delivered monochromatic 337-nm pulses, each with a half-amplitude pulse-width of $3 \mathrm{~ns}$, and an objective (40×; Unitron) was used to concentrate the excitation beam on the microscopic sample. Emitted photons were collected and focused on a photomultiplier 1P28 (Hamamatsu Corporation, Japan). A diaphragm placed on the emission pathway allowed the selection of signals from single cells, while a 404-nm bandpass filter (half bandwidth; $40 \mathrm{~nm}$ ) also located along the emission pathway was used to select the pyrene emission. Each signal was digitalized by a digital oscilloscope (TDS 3032C; Tektronix, USA). The 245 fluorescent decay of single PBA-loaded cells selected by the 404-nm filter could be resolved into three exponential curves. The time constants (i.e. lifetimes) and amplitude values of each exponential curve in the decay were obtained using the downhill simplex method (Nelder and Mead, 1965). The first two decays corresponded to the intrinsic fluorescence of the cell attributed to the reduced form of $\mathrm{NAD}(\mathrm{P}) \mathrm{H}$. The third long-time constant ( $>100 \mathrm{~ns})$, which was characteristic of 
pyrene derivatives, was related to the ROS concentration through the Stern-Volmer equation (Stern 251 and Volmer, 1919) that describes collisional fluorescent quenching of a probe (i.e. PBA) by a 252 quencher (i.e., free radicals). The method has been described in several papers (Ribou et al., 2003; 253 Ribou et al., 2004; Rharass et al., 2006). We calculated the variation of intracellular ROS 254 concentrations as follows:

$$
[\operatorname{ROS}] /[\operatorname{ROS}]_{\mathrm{m}}=\left[\mathrm{t}_{\mathrm{m}}\left(\mathrm{t}_{0}-\mathrm{t}\right)\right] /\left[\mathrm{t}\left(\mathrm{t}_{0}-\mathrm{t}_{\mathrm{m}}\right)\right] \quad \text { Equation } 1
$$

256 where $t$ is the fluorescent lifetime measured for 108 single hemocytes originating from eight $257 \mathrm{BgBRE}$ snails and 111 cells from eight $\mathrm{BgGUA}$ snails; $\mathrm{t}_{\mathrm{m}}$ is the mean of all lifetimes; and $\mathrm{t}_{0}$ is the 258 fluorescent lifetime in the absence of ROS (measured from dead hemocytes fixed with Baker 259 solution). In this equation, $[\mathrm{ROS}]_{\mathrm{m}}$ is the mean of the concentrations from all tested cells (219 260 cells). We assumed that fixation ended all cellular activity and ROS production. In the presented 261 data, the mean ROS concentration has been assigned an arbitrary value of 1.

The $\mathrm{H}_{2} \mathrm{O}_{2}$ production by hemocytes was measured using Amplex® Red (Invitrogen). Hemolymph was collected from the head-foot regions of $\mathrm{BgBRE}$ and $\mathrm{BgGUA}$ snails (7-11 mm in diameter) as previously described (Bouchut et al., 2006), and the number of hemocytes per $\mu 1$ of 267 hemolymph was quantified using a cell counter (Z Series Coulter Counter; Beckman Coulter); $268226.2 \pm 50.6$ cells $/ \mu 1$ and $241.2 \pm 102.1$ cells $/ \mu 1$ were obtained for $B g B R E$ and $B g G U A$, 269 respectively. The Hemolymph of four snails was pooled and 45,000 hemocytes per well were 270 dispensed to a 96-well plate for each strain. The hemocytes were allowed to adhere and spread for 1 $271 \mathrm{~h}$ at $26^{\circ} \mathrm{C}$. The plate was then centrifuged $(600 \mathrm{~g}$ for $10 \mathrm{~min})$, the plasma was removed, the adhered 272 hemocytes were washed three times with HBSS, and the wells were treated with Amplex ${ }^{\circledR}$ Red 273 reaction mixture (100 $\mu \mathrm{L}$ per well, prepared according to the manufacturer's instructions). Optical 274 density was measured with a microplate reader at $570 \mathrm{~nm}$ during the following $1 \mathrm{~h}($ at $5,10,15,20$, $27530,40,50,60 \mathrm{~min})$. The results are expressed as Amplex Red O.D. at $570 \mathrm{~nm} /$ 45,000 cells. 
2.10. Biomphalaria glabrata superoxide anion plasma content

The plasma content of superoxide anion was monitored via the superoxide-mediated reduction of nitroblue tetrazolium (NBT), which results in the precipitation of an insoluble blue formazan that can be quantified spectrophotometrically. Briefly, hemolymph was collected from $\mathrm{BgBRE}$ and $\mathrm{BgGUA}$ snails as described above. Hemocytes were removed by centrifugation $(1,500$ $g$ for $15 \mathrm{~min}$ ), and then $50 \mu \mathrm{L}$ of plasma from each snail was mixed with $50 \mu \mathrm{lof} 0.1 \%$ NBT (Sigma) dissolved in PBS; $\left(\mathrm{Na}_{2} \mathrm{HPO}_{4} 8.41 \mathrm{mM}, \mathrm{NaH}_{2} \mathrm{PO}_{4} 1.65 \mathrm{mM}, \mathrm{NaCl} 45.34 \mathrm{mM}, \mathrm{pH} 7.45\right)$. Formazan blue formation was measured with a microplate reader at $620 \mathrm{~nm}$ over the course of $3 \mathrm{~h}$ (at 5, 10, 15, 30, 60, 90, $180 \mathrm{~min}$ ). NBT-free plasma was used as a control, and triplicate experiments were conducted for 10 individuals per strain.

\subsection{Statistical analyses}

The normality of our experimental data was assessed using the Shapiro-Wilk normality test (Shapiro and Wilk, 1965). Our data on the effect of $\mathrm{H}_{2} \mathrm{O}_{2}$ cytotoxicity on S. mansoni sporocysts

(LDH test), B. glabrata hemocyte $\mathrm{H}_{2} \mathrm{O}_{2}$ production, and superoxide anion plasma content were all found to be normally distributed $(P>0.05)$, and were subsequently analyzed using the student's $t$ test. Our data on the effect of $\mathrm{H}_{2} \mathrm{O}_{2}$ on $S$. mansoni sporocyst mortality and the total antioxidant capacity of sporocysts were not normally distributed $(P<0.05)$, and were subsequently analyzed using the Mann-Whitney test. The results of the ROS concentration assays in each mollusk strain were analyzed using the Mann-Whitney test. The Kolmogorov-Smirnov two-samples test was utilized to determine whether the ROS concentrations were similarly distributed in hemocytes from $\mathrm{BgBRE}$ and $\mathrm{BgGUA}$.

\section{Results}


Two different assays were conducted to test the effect of $\mathrm{H}_{2} \mathrm{O}_{2}$ on the two strains of $S$.

303 mansoni sporocysts (SmBRE and SmGH2) (Fig. 1). First, an LDH test was used to examine the 304 cytotoxicity of $\mathrm{H}_{2} \mathrm{O}_{2}$ on sporocysts of each strain. Our results revealed that the susceptibility to $305 \mathrm{H}_{2} \mathrm{O}_{2}$ was significantly higher for SmGH2 than SmBRE (Fig. 1A). When exposed to $200 \mu \mathrm{M} \mathrm{H}_{2} \mathrm{O}_{2}$, 306 SmGH2 sporocysts showed $25.8 \%$ cytotoxicity (i.e., $25.8 \%$ of the cells had lysed and released their 307 LDH content), whereas no changes were observed for $\mathrm{SmBRE}$ at the same $\mathrm{H}_{2} \mathrm{O}_{2}$ concentration (Fig. 308 1A). However, although cell lysis occurred in $\mathrm{SmGH} 2$, the sporocysts were still alive at this 309 concentration. To investigate possible between-strain differences in mortality, we next exposed 310 sporocytes to increasing concentrations of $\mathrm{H}_{2} \mathrm{O}_{2}$ and examined motility and the beating of the 311 flame-cell flagella, which were taken as distinguishing between living and dead larvae. No 312 difference between the two strains was observed until the concentration of $\mathrm{H}_{2} \mathrm{O}_{2}$ reached 1,600 $\mu \mathrm{M}$ 313 (Fig. 1B). At this concentration, $31.2 \%$ and $2.6 \%$ of the SmGH2 and SmBRE sporocysts were dead, 314 respectively; this difference is statistically significant (student's $t$-test; $P=0.017$ ). These results 315 suggest that $\mathrm{SmGH} 2$ sporocysts are more susceptible to $\mathrm{H}_{2} \mathrm{O}_{2}$ than $S m B R E$ sporocysts.

\subsection{The total antioxidant capacity of S. mansoni sporocysts}

To investigate potential differences in the constitutive antioxidant abilities of sporocysts from SmBRE and SmGH2, we measured the cumulative antioxidant activities of these two strains (Fig. 2). Our results revealed that the antioxidant ability of SmGH2 was significantly lower than that of SmBRE (approximately 13\% less; Mann-Whitney test, $P=0.0001$ ).

3.3. Reverse Transcription-quantitative PCR of ROS-scavenger expression among S. mansoni strains

RT-qPCR was used to compare the expression of parasite antioxidant enzymes suspected to play key roles in the detoxification of host-induced oxidative stress (Table 1) (Guillou et al., 2007). Notably, Cu-Zn SOD (Smp_176200.2) was found to be expressed at a significantly higher level in 
SmBRE than in SmGH2 (2.7-fold; $P=0.017)$ (Fig. 3). In contrast, no difference was observed in the expression levels of glyceraldehyde-3-phosphate dehydrogenase (GAPDH, Smp_056970.1), GST omega (Smp_152710.1), GST 28 kD (Smp_054160), GST 26 kD (Smp_163610), glyoxalase II (Smp_091010) or thioredoxin peroxidase (TPX, Smp_158110) (data not shown).

\subsection{Intracellular ROS measurements in single B. glabrata hemocytes}

We monitored intracellular ROS levels in single hemocytes, using PBA. This method allows global ROS to be measured without interference from the reactive hydroxyl radical or $\mathrm{H}_{2} \mathrm{O}_{2}$. PBA fluorescent lifetimes were measured for 108 and 111 individual hemocytes originating from eight BgBRE and eight $\mathrm{BgGUA}$ snails, respectively. BgBRE hemocytes produced significantly (11.2\%) more ROS than BgGUA hemocytes (Mann-Whitney test; $P=0.009$ ) (Fig. 4A). Fig. 4B shows the distribution of hemocytes from both strains according to their ROS concentrations, which were calculated from the ratio given in equation 1 (see Materials and methods section 2.8.2.). Although the cells from both $\mathrm{BgBRE}$ and $\mathrm{BgGUA}$ samples were distributed around the mean ROS concentration, their distributions were significantly different (Kolmogorov-Smirnov test, $P=$ 0.012). Among the hemocytes producing more than 1.5 -fold of the mean ROS concentration, $68.8 \%$ were from BgBRE strain, while only $31.2 \%$ were from BgGUA. Conversely, among the hemocytes that showed the lowest ROS concentrations ( $<0.7$-fold of the mean ROS concentration) $38.1 \%$ were from $\mathrm{BgBRE}$ and $62 \%$ were from $\mathrm{BgGUA}$ (Fig. 4B). By recording the fluorescent lifetimes of single cells loaded with PBA, we also obtained the relative concentrations of free and bound $\mathrm{NAD}(\mathrm{P}) \mathrm{H}$ (an indicator of metabolic change) in each cell. However there was no significant difference in the quantity of bound and free $\mathrm{NAD}(\mathrm{P}) \mathrm{H}$ (mean ratio $=0.60$ for both strains; data not shown), suggesting that the strains had similar levels of metabolism. Thus, the only molecular difference observed between the two strains was the level of ROS production.

\section{5. $\mathrm{H}_{2} \mathrm{O}_{2}$ production and release by $\mathrm{B}$. glabrata hemocytes}


We assessed $\mathrm{H}_{2} \mathrm{O}_{2}$ production and secretion by hemocytes of both strains using Amplex

Red. Fig. 5 shows the cumulative amount of $\mathrm{H}_{2} \mathrm{O}_{2}$ constitutively released by hemocytes of each strain over $1 \mathrm{~h}$. The maximum level of $\mathrm{H}_{2} \mathrm{O}_{2}$ production was reached at 20 min for $\mathrm{BgGUA}$ and at 40 min for BgBRE after addition of Amplex Red substrate. In total, BgBRE hemocytes produced significantly more (1.44-fold; mean value) $\mathrm{H}_{2} \mathrm{O}_{2}$ than BgGUA hemocytes (student's $t$-test; $P<0.05$ ) (Fig. 5).

\subsection{Biomphalaria glabrata superoxide anion plasma content}

To our knowledge, all spectrophotometric methods currently available for the determination of $\mathrm{H}_{2} \mathrm{O}_{2}$ are based on the measurement of red or orange pigments, making these methods unsuitable for use on B. glabrata plasma samples, which are already tinted red by hemoglobin. Consequently, we used NBT to measure the amount of superoxide anion $\left(\mathrm{O}_{2}{ }^{-\cdot}\right.$; a precursor of $\left.\mathrm{H}_{2} \mathrm{O}_{2}\right)$ produced in both strains. As shown in Fig. 6, at $3 \mathrm{~h}$ after addition of NBT BgBRE plasma contained significantly more (44\% more) superoxide anion than BgGUA plasma (student's $t$-test; $P=0.0007$ ).

\subsection{Compatibility of sympatric and allopatric S. mansoni/B. glabrata combinations}

Sympatric pairings of S. mansoni and B. glabrata originating from Brazil and Guadeloupe were previously shown to display different levels of compatibility that remained remarkably stable across laboratory generations (Théron et al., 2008). We first used dose-response curves obtained by challenging snails with increasing doses of miracidia to confirm that similar differences could be observed between our strains. At doses of 10 or more miracidia/snail, SmBRE/BgBRE showed an infection rate of $100 \%$, while $\mathrm{SmGH} 2 / \mathrm{BgGUA}$ had an infection rate of approximately half that, at around 55\%. Interestingly, differences were also observed for the number of parasites (SpI) that develop within the snails. The infection intensity rose gradually as the challenge doses increased for SmBRE/BgBRE, reaching $16.18 \pm 0.86$ parasites/snail at the 50 -miracidia dose. In contrast, the 
379 infection intensity for $\mathrm{SmGH} 2 / \mathrm{BgGUA}$ remained low regardless of the challenge dose, varying 380 between $1.6 \pm 0.20$ and $3.2 \pm 0.64$ parasites/snail (Fig. 7).

381 When we tested the heterologous combinations, we found that the $S m \mathrm{BRE} / \mathrm{Bg} \mathrm{GUA}$ pairing 382 showed a substantial level of compatibility, with infection rates of $80-90 \%$ (not significantly 383 different from the $100 \%$ achieved by the SmBRE/BgBRE pairing), but with lower parasite intensities 384 (9.8 \pm 0.89 for the 50 -miracidia dose) compared with the sympatric combination $(16.18 \pm 0.86$ 385 parasites/snail at the 50-miracidia dose). In contrast, the $\mathrm{SmGH} 2 / \mathrm{BgBRE}$ combination showed very 386 little infectivity, with infection rates $<6 \%$ and $\sim 1$ parasite/snail regardless of the challenge dose 387 (Fig. 7).

3.8. ROS, ROS scavengers and compatibility in sympatric and allopatric S. mansoni/B. glabrata combinations

The above-described results indicated that levels of ROS and ROS scavengers were correlated in both sympatric combinations, with high-level ROS/ROS scavenger production in the 393 Brazilian combination, but lower-level ROS/ROS scavenger production in the Guadeloupean combination. If high levels of $S$. mansoni ROS scavenger are correlated with better resistance of the intramolluskan stage of the parasite (as we hypothesized), we would expect SmGH2 to have a relatively low ability to infect the allopatric BgBRE snails, while SmBRE would have a high ability to infect the allopatric BgGUA snails. This hypothesis was verified in our model, as shown in Fig. 8.

\section{Discussion}

Snail-schistosome compatibility and infection rates result from a complex interplay between the host's defense mechanisms and the parasite's infectivity strategies. Due to selective pressures

403 exerted by the parasite on the host and vice versa, co-evolutionary dynamics may be observed 404 (Janzen, 1980; Howard, 1991). Between-population or between-strain differences in the outcomes 
of such evolutionary processes may be expected due to differences in the epidemiological and environmental conditions, and/or genetic architectures. Such differential selection patterns could explain, at least in part, the geographic and/or strain-specific compatibility variations seen in snailschistosome interactions (Théron et al., 2008). At present, however, there is relatively little empirical evidence demonstrating reciprocal molecular adaptations in both host and parasite.

Here, we investigated the interaction between $S$. mansoni and the snail, B. glabrata, as this interaction is a popular model for the study of co-evolutionary dynamics (Beltran and Boissier, 2008; Beltran et al., 2008; Bouchut et al., 2008; Roger et al., 2008a; Roger et al., 2008b; Roger et al., 2008c; Steinauer, 2009). We confirmed that there are different levels of compatibility between two geographic strains of S. mansoni and their sympatric snail hosts, B. glabrata (Fig. 7) that both have co-evolved independently. We compared the host oxidant and parasite antioxidant abilities that appear to form the core of the attack/defense interactions of these two pairings.

ROS are the main effectors of the snail immune system; they are highly reactive and can trigger irreversible cell damage. Indeed, ROS produced by the hemocytes of B. glabrata are known to play a crucial role in the killing of S. mansoni (Hahn et al., 2000; Hahn et al., 2001a, b; Bender et al., 2005; Bayne, 2009). Conversely, S. mansoni possess antioxidant systems capable of counteracting the ROS produced by their host's immune system. Schistosoma mansoni is exposed to ROS in both their intermediate (snail) and definitive (human or mammalian) hosts, and produce oxidative-stress scavengers in their excretory-secretory products (ESP) during all stages of their life cycle (Mei and LoVerde, 1997; Curwen et al., 2004; Zelck and Von Janowsky, 2004; Knudsen et al., 2005; van Balkom et al., 2005; Bernal et al., 2006; Dzik, 2006; Perez-Sanchez et al., 2006; Cass et al., 2007; Guillou et al., 2007; Mourao et al., 2009a; Wu et al., 2009). Therefore, the success or failure of host invasion by $S$. mansoni depends at least in part on its ability to defend itself against oxidative damage (Mourao et al., 2009a). In this system, therefore, ROS and ROS scavengers should be involved in a co-evolutionary arms race, and we would expect their respective production levels in sympatric host/parasite combinations to be closely related. 
As previous studies have established that $\mathrm{H}_{2} \mathrm{O}_{2}$ is the main ROS involved in killing $S$. mansoni sporocysts, probably due to its stability and capacity to cross cell membranes (Hahn et al., 433 2001b; Bienert et al., 2006), we studied the susceptibility of two strains of S. mansoni to $\mathrm{H}_{2} \mathrm{O}_{2}$. Our 434 results showed a clear intrinsic difference between parasites isolated from two different geographic regions: the intramolluskan stages of Guadeloupean S. mansoni ( $\mathrm{SmGH} 2$ ) were more sensitive to $\mathrm{H}_{2} \mathrm{O}_{2}$ than those of the Brazilian strain (SmBRE) (Fig. 1). Moreover, we observed a difference in antioxidant potential between strains, with $\mathrm{SmGH} 2$ displaying a lower level of antioxidant activity than SmBRE (Fig. 2). Thus, SmBRE has a more efficient antioxidant system, which would seem to explain its higher level of resistance to $\mathrm{H}_{2} \mathrm{O}_{2}$-mediated oxidative damage.

In order to identify the molecular pathways involved in these differential antioxidant properties, we investigated the strain-specific transcription levels of genes encoding various antioxidant enzymes, including GAPDH (Smp_056970.1), GST omega (Smp_152710.1), GST28 443 (Smp_054160), GST26 (Smp_163610), glyoxalase II (Smp_091010), thioredoxin peroxidase, and 444 Cu-Zn SOD (Smp_176200.2) (Guillou et al., 2007; Vermeire and Yoshino, 2007; Roger et al., 2008c; Mourao et al., 2009a; Wu et al., 2009). Among these candidates, only the Cu-Zn SOD mRNA displayed differential expression, with expression levels that were 2.7-fold higher in SmBRE than in SmGH2 (Fig. 3). This finding is consistent with our protein-level results from a 448 previous proteomic study (Roger et al., 2008c), and these observations collectively suggest that $\mathrm{Cu}-$ 449 Zn SOD plays a key role in the antioxidant strategy of S. mansoni. The involvement of Cu-Zn SOD in ROS detoxification is a recurring and intriguing question, because it is capable of dismutating the 451 superoxide anion $\left(\mathrm{O}_{2}{ }^{-}\right)$to produce $\mathrm{H}_{2} \mathrm{O}_{2}$ (Zelck and Von Janowsky, 2004; Guillou et al., 2007; 452 Mourao et al., 2009a). The hypothesis currently used to explain the role of S. mansoni Cu-Zn SOD 453 in ROS detoxification is based on a suspected peroxidative function (Yim et al., 1993; Yim et al., 454 1996; Kim and Kang, 1997; Bayne et al., 2001). In short, it has been proposed that S. mansoni Cu$455 \mathrm{Zn}$ SOD could use its own dismutation product $\left(\mathrm{H}_{2} \mathrm{O}_{2}\right)$ to produce hydroxyl radicals $\left(\mathrm{HO}^{\circ}\right)$ that are 456 less toxic for sporocysts (Bayne et al., 2001). 
In a co-evolutionary context, the between-strain differences in ROS susceptibility and

458 antioxidant activity of these $S$. mansoni strains suggest that there could be comparable differences 459 in the ROS production capabilities of the host snail strains. To test this hypothesis, we investigated 460 ROS production by the two snail strains. First, we used a fluorescence-based method (Rharass et al., 461 2006) to investigate the hemocyte production of free-radicals such as nitric oxide and superoxide 462 anion. This approach revealed that $\mathrm{BgBRE}$ snails produced more free radicals than $\mathrm{BgGUA}$ snails 463 (Fig. 4A). Moreover, a distribution analysis of free-radical concentrations in single hemocytes 464 showed that the cells producing higher concentrations of ROS came from BgBRE individuals, while those producing lower levels of free radicals were from BgGUA snails (Fig. 4B).

However, although our results revealed that global ROS production differed between BgBRE and BgGUA, oxidants can differ in their reactivity and efficient parasite killing requires that the host produce the right oxidant (Bayne et al., 2001). As previous studies have demonstrated the crucial role of hydrogen peroxide $\left(\mathrm{H}_{2} \mathrm{O}_{2}\right)$ in the killing of $S$. mansoni sporocysts (Hahn et al., 2001b; Goodall et al., 2004; Bender et al., 2005; Bender et al., 2007), we investigated potential differences in hemocyte $\mathrm{H}_{2} \mathrm{O}_{2}$ production between the snail strains. Our results showed that hemocytes from $B g$ BRE constitutively produced more $\mathrm{H}_{2} \mathrm{O}_{2}$ than those from $B g$ GUA (Fig. 5). We then examined the $\mathrm{H}_{2} \mathrm{O}_{2}$ content of plasma from these snails. As technical restrictions make it impossible to directly measure $\mathrm{H}_{2} \mathrm{O}_{2}$ in plasma, we measured the superoxide anion, which is a precursor of $\mathrm{H}_{2} \mathrm{O}_{2}$ (Selkirk et al., 1998). Our results confirmed that $\mathrm{BgBRE}$ plasma contained significantly more superoxide anion than BgGUA plasma (Fig. 6). All of these data were obtained from hemocytes harvested from uninfected snails and without cell stimulation. Notably, no difference in ROS production was observed when these hemocytes were stimulated by the addition of phorbol 12-myristate 13-acetate (PMA) to culture medium (data not shown).

Taken together, our data show that: (i) the production of ROS in general and $\mathrm{H}_{2} \mathrm{O}_{2}$ (the main 481 ROS acting against S. mansoni sporocysts) in particular differ between the two snail strains; and (ii) this $\mathrm{H}_{2} \mathrm{O}_{2}$ production seems to be correlated with the level of ROS scavengers produced by 
sympatric parasites. $\mathrm{BgBRE}$ snails produce higher amounts of $\mathrm{H}_{2} \mathrm{O}_{2}$ and interact naturally with

484 SmBRE, which have better resistance against oxidative stress, while BgGUA snails produce less $485 \mathrm{H}_{2} \mathrm{O}_{2}$ and are sympatric with $\mathrm{SmGH}$, which is more susceptible to ROS. If our hypothesis is accurate, therefore, we would expect our cross-infection experiments to reveal differences: (i) in the infective potential of our two S. mansoni strains; and (ii) in the resistance potential of our two $B$. glabrata strains.

Indeed, the results of the infection and cross-infection experiments showed significant differences in the infection rates and intensities (Fig. 7). The factors and mechanisms underlying these differences are not yet known, but may include historical epidemiological conditions, differential selective pressures in the transmission areas, genotypic diversities in the host and parasitic isolates, recognition mechanisms developed through the matching-phenotypes model, and intraspecific competition among sporocysts (for details, see (Théron et al., 1997; Théron and 495 Coustau, 2005; Théron et al., 2008; Bech et al.). Notably, the host-parasite combination characterized by the higher infection rates and parasite intensities (SmBRE/BgBRE) was also characterized by a higher ROS-production capacity by the host and a higher ROS-scavenging ability by the parasite. In contrast, the host-parasite combination with lower infection rates and parasite intensities ( $\mathrm{SmGH} 2 / \mathrm{BgGUA}$ ) showed lower ROS production by the host and lower ROS 500 scavenging by the parasite (Fig. 8). These observations argue for the presence of reciprocal 501 adaptation between the ROS and ROS scavenger traits. This was further supported by the results from our allopatric cross-infections. The $\mathrm{SmGH} 2$ strain, which had co-evolved with its sympatric snail (BgGUA) to produce lower levels of ROS, could not effectively infect high-ROS-producing BgBRE snails (Figs. 7 and 8). Conversely, the SmBRE strain, which had co-evolved with a host that 505 produced more ROS (BgBRE), could easily infect low-ROS-producing BgGUA snails (Figs. 7 and 8). Interestingly, however, the infection success of SmBRE was lower for the allopatric combination than the sympatric pairing (Figs. 7 and 8), suggesting that the oxidative factors probably act in combination with other factors to determine the outcome of the B. glabrata/S. mansoni interaction. 
Within hosts, immune effectors exert the main selective pressure on parasites (Loker and

510 Adema, 1995; Damian, 1997). However, another factor that helps to define the interaction is the

511 efficiency of parasite recognition by snail immune receptors, and the ability of the parasite to escape

512 this recognition. We previously discovered a group of polymorphic antigens of $S$. mansoni (the $S$.

513 mansoni polymorphic mucins, SmPoMucs) (Roger et al., 2008a; Roger et al., 2008b; Roger et al., 514 2008c), and recently showed that these antigens are recognized by diversified B. glabrata immune 515 receptors (the fibrinogen-related proteins, FREPs) (Moné et al., 2010a). These reports on the 516 molecular interactions underlying snail-schistosome compatibility suggest that co-evolutionary 517 (reciprocal adaptation) processes probably occur through a combination of changes in general 518 resistance (ROS/ROS scavengers) and more specific interactions (FREPs/SmPoMucs). In non519 specific resistance/infectivity interactions involving density-dependant forces (e.g., the number of 520 developing parasites within the host), co-evolution leads to global increases in the amount of 521 attack/defense products, such as the interplay of ROS and ROS scavengers described herein. In 522 highly specific genotype-by-genotype interactions, such as recognition/evasion processes, however, 523 co-evolution leads to increases in the diversification and/or polymorphisms among specific 524 molecules, as observed for FREPs and SmPoMucs.

Even if the success of infection is not exclusively based on the levels of ROS and ROS scavengers, our model of dynamic co-evolution predicts that a change in parasite virulence or host resistance would be associated with life history trade-offs (reallocation of resources), with increased production of a molecule under co-evolutionary pressure yielding indirect negative consequences 529 for other functions (development, growth, fecundity, reproductive rate, etc.) (Green et al., 2000; 530 Lohse et al., 2006; Forde et al., 2008). Indeed, this kind of trade-off has been observed in our 531 model, as a previous study showed that cumulative cercarial production was two-fold higher for the $532 \mathrm{SmGH} 2 / \mathrm{BgGUA}$ combination than for the SmBRE/BgBRE (Théron et al., 1997). This could 533 indicate that SmBRE has made a tradeoff by investing in the production of ROS scavengers at the 534 expense of producing cercariae. 
In summary, host-parasite interactions are dynamic biological systems in which the host's

536 defense mechanisms face the parasite's infectivity mechanisms, leading to a co-evolutionary arms race (Combes, 2000; Howard and Jack, 2007).

Developing correlation approaches to studying co-evolution have some limitations. Indeed

539 the correlations between traits of interacting species cannot always provide unequivocal evidence

540 for co-evolution. Reciprocity could also occur and an absence of correlated traits is not evidence for 541 an absence of co-evolution (Nuismer et al., 2007; Nuismer et al., 2010; Yoder and Nuismer, 2010).

542 Non-co-evolutionary mechanisms could explain correlations between the traits of interacting 543 species. For example, the correlation could result from a colonization process in which a parasite 544 species with new potential arrived in a new environment and is more well-adapted to the sympatric 545 interacting species. In other interaction models correlated traits could evolve if the abiotic or biotic 546 environments favour similar traits in both of the interacting species. For example, a biotic selection 547 that affects only one of the interacting species can itself cause trait matching. This can occur if 548 interactions have potent fitness consequences for only one of the species or if the outcome of 549 interactions depends on the phenotype of only one of the species. These one-way interactions can 550 generate correlations that are indistinguishable from those that evolve due to co-evolutionary 551 processes (Nuismer et al., 2007; Nuismer et al., 2010; Yoder and Nuismer, 2010). In our model of 552 interest B. glabrata could be infected by a lot of pathogens species (other than S. mansoni) that 553 represent a selective pressure that could enhance snail ROS production. In this context, 554 schistosomes for which the specificity for the intermediate snail host is very high will still succeed 555 in infecting the snails, only if they are able to circumvent ROS by increasing their ROS scavenger 556 production.

However, Nuismer et al. $(2007,2010)$ state that correlation could occur if interactions are 558 mediated by a mechanism of phenotype matching such as what takes place for host-parasite 559 interactions. This phenotype matching process was proposed for our S. mansoni / B. glabrata model 560 of interest (Théron and Coustau, 2005). 
Therefore whatever are the mechanisms involved in the apparition of trait correlation

562 between two interacting species, our present results reveal the existence of phenotypic matching

563 between host and parasitic strains in terms of their attack (ROS production) and defense (ROS 564 scavenging) traits. To our knowledge, this work provides the first example of a clear link between 565 the level of oxidant and antioxidant molecules possibly resulting from sympatric co-evolution, and 566 provides supporting evidence for a field illustration of the Red Queen Hypothesis (Van Valen, 567 1974) and its predictions of a functional trait in a metazoan host/parasite model. Detailed 568 mechanistic studies will be conducted in multiple populations to fully confirm the link between 569 correlated traits and the Red Queen context.

\section{Acknowledgments}

We thank Bernard Dejean and Anne Rognon for technical assistance; Dr. Carole Blanchard for advice on measuring ROS levels in plasma; and Julien Portela for helping with the ROS titration experiments. The work received funding from the Schistophepigen (ANR-07-BLAN-0119-02) and BiomGenIm (ANR-07-BLAN-0214-03) programs of the French National Agency for Research, Centre National de la Recherche Scientifique, and Université de Perpignan Via Domitia. The funders had no role in the study design, data collection, data analysis, the decision to publish or manuscript preparation.

\section{References}

581 Bahia, D., Avelar, L., Mortara, R.A., Khayath, N., Yan, Y., Noel, C., Capron, M., Dissous, C., 582 Pierce, R.J., Oliveira, G., 2006. SmPKC1, a new protein kinase C identified in the platyhelminth 583 parasite Schistosoma mansoni. Biochem. Biophys. Res. Commun. 345, 1138-1148.

584 Bayne, C.J., 2009. Successful parasitism of vector snail Biomphalaria glabrata by the human blood 
Bayne, C.J., Hahn, U.K., Bender, R.C., 2001. Mechanisms of molluscan host resistance and of 587 parasite strategies for survival. Parasitology 123 Suppl, S159-167.

588 Bech, N., Beltran, S., Portela, J., Rognon, A., Allienne, J.F., Boissier, J., Theron, A., 2010. Followup of the genetic diversity and snail infectivity of a Schistosoma mansoni strain from field to laboratory. Infect. Genet. Evol. 10, 1039-1045.

Beltran, S., Boissier, J., 2008. Schistosome monogamy: who, how, and why? Trends Parasitol. 24, 386-391.

Beltran, S., Cezilly, F., Boissier, J., 2008. Genetic dissimilarity between mates, but not male heterozygosity, influences divorce in schistosomes. PLoS ONE 3, e3328.

Bender, R.C., Broderick, E.J., Goodall, C.P., Bayne, C.J., 2005. Respiratory burst of Biomphalaria glabrata hemocytes: Schistosoma mansoni-resistant snails produce more extracellular $\mathrm{H} 2 \mathrm{O} 2$ than susceptible snails. J. Parasitol. 91, 275-279.

Bender, R.C., Goodall, C.P., Blouin, M.S., Bayne, C.J., 2007. Variation in expression of

Biomphalaria glabrata SOD1: a potential controlling factor in susceptibility/resistance to

600 Schistosoma mansoni. Dev. Comp. Immunol. 31, 874-878.

601 Bernal, D., Carpena, I., Espert, A.M., De la Rubia, J.E., Esteban, J.G., Toledo, R., Marcilla, A., 602 2006. Identification of proteins in excretory/secretory extracts of Echinostoma friedi (Trematoda) 603 from chronic and acute infections. Proteomics 6, 2835-2843.

604 Bienert, G.P., Schjoerring, J.K., Jahn, T.P., 2006. Membrane transport of hydrogen peroxide. 605 Biochim. Biophys. Acta 1758, 994-1003.

606 Bouchut, A., Roger, E., Gourbal, B., Grunau, C., Coustau, C., Mitta, G., 2008. The compatibility 607 polymorphism in invertebrate host/trematodes interactions: research of molecular determinants. 608 Parasite 15, 304-309.

609 Bouchut, A., Sautiere, P.E., Coustau, C., Mitta, G., 2006. Compatibility in the Biomphalaria 610 glabrata/Echinostoma caproni model: Potential involvement of proteins from hemocytes revealed 611 by a proteomic approach. Acta Trop. 98, 234-246. 
612 Cass, C.L., Johnson, J.R., Califf, L.L., Xu, T., Hernandez, H.J., Stadecker, M.J., Yates, J.R., 3rd, 613 Williams, D.L., 2007. Proteomic analysis of Schistosoma mansoni egg secretions. Mol. Biochem. 614 Parasitol. 155, 84-93.

615 Chernin, E., 1963. Observations on hearts explanted in vitro from the snail Australorbis glabratus. 616 The Journal of parasitology 49, 353-364.

617 Combes, C., 2000. Selective pressure in host-parasite systems. J. Soc. Biol. 194, 19-23.

618 Curwen, R.S., Ashton, P.D., Johnston, D.A., Wilson, R.A., 2004. The Schistosoma mansoni soluble 619 proteome: a comparison across four life-cycle stages. Mol. Biochem. Parasitol. 138, 57-66.

620 Damian, R.T., 1997. Parasite immune evasion and exploitation: reflections and projections. 621 Parasitology 115 Suppl, S169-175.

622 de Jong-Brink, M., Bergamin-Sassen, M., Solis Soto, M., 2001. Multiple strategies of schistosomes 623 to meet their requirements in the intermediate snail host. Parasitology 123 Suppl, S129-141.

624 Dybdahl, M.F., Storfer, A., 2003. Parasite local adaptation: Red Queen versus Suicide King. Trends 625 in ecology \& evolution $18,523-530$.

626 Dzik, J.M., 2006. Molecules released by helminth parasites involved in host colonization. Acta 627 Biochim. Pol. 53, 33-64.

628 Forde, S.E., Thompson, J.N., Bohannan, B.J., 2004. Adaptation varies through space and time in a 629 coevolving host-parasitoid interaction. Nature 431, 841-844.

630 Forde, S.E., Thompson, J.N., Holt, R.D., Bohannan, B.J., 2008. Coevolution drives temporal 631 changes in fitness and diversity across environments in a bacteria-bacteriophage interaction. 632 Evolution 62, 1830-1839.

633 Gagneux, S., DeRiemer, K., Van, T., Kato-Maeda, M., de Jong, B.C., Narayanan, S., Nicol, M., 634 Niemann, S., Kremer, K., Gutierrez, M.C., Hilty, M., Hopewell, P.C., Small, P.M., 2006. Variable 635 host-pathogen compatibility in Mycobacterium tuberculosis. Proc. Natl. Acad. Sci. U. S. A. 103, $636 \quad 2869-2873$. 
637 Gasnier, N., Rondelaud, D., Abrous, M., Carreras, F., Boulard, C., Diez-Banos, P., Cabaret, J., 638 2000. Allopatric combination of Fasciola hepatica and Lymnaea truncatula is more efficient than 639 sympatric ones. Int. J. Parasitol. 30, 573-578.

640 Gerard, C., Balzan, C., Theron, A., 1995. Spatial distribution patterns of the sporocyst 641 infrapopulation of Schistosoma mansoni within its mollusc host (Biomphalaria glabrata): an 642 unusual phenotype of aggregation. J. Parasitol. 81, 310-312.

643 Goodall, C.P., Bender, R.C., Broderick, E.J., Bayne, C.J., 2004. Constitutive differences in Cu/Zn 644 superoxide dismutase mRNA levels and activity in hemocytes of Biomphalaria glabrata (Mollusca) 645 that are either susceptible or resistant to Schistosoma mansoni (Trematoda). Mol. Biochem. 646 Parasitol. 137, 321-328.

647 Green, D.M., Kraaijeveld, A.R., Godfray, H.C., 2000. Evolutionary interactions between 648 Drosophila melanogaster and its parasitoid Asobara tabida. Heredity 85 Pt 5, 450-458.

649 Guillou, F., Mitta, G., Dissous, C., Pierce, R., Coustau, C., 2004. Use of individual polymorphism 650 to validate potential functional markers: case of a candidate lectin (BgSel) differentially expressed 651 in susceptible and resistant strains of Biomphalaria glabrata. Comp. Biochem. Physiol. B Biochem. 652 Mol. Biol. 138, 175-181.

653 Guillou, F., Roger, E., Moné, Y., Rognon, A., Grunau, C., Theron, A., Mitta, G., Coustau, C., 654 Gourbal, B.E., 2007. Excretory-secretory proteome of larval Schistosoma mansoni and 655 Echinostoma caproni, two parasites of Biomphalaria glabrata. Mol. Biochem. Parasitol. 155, 4565656.

657 Hahn, U.K., Bender, R.C., Bayne, C.J., 2000. Production of reactive oxygen species by hemocytes 658 of Biomphalaria glabrata : carbohydrate-specific stimulation. Dev. Comp. Immunol. 24, 531-541. 659 Hahn, U.K., Bender, R.C., Bayne, C.J., 2001a. Involvement of nitric oxide in killing of Schistosoma 660 mansoni sporocysts by hemocytes from resistant Biomphalaria glabrata. J. Parasitol. 87, 778-785. 
661 Hahn, U.K., Bender, R.C., Bayne, C.J., 2001b. Killing of Schistosoma mansoni sporocysts by 662 hemocytes from resistant Biomphalaria glabrata: role of reactive oxygen species. The Journal of 663 parasitology 87, 292-299.

664 Howard, J.C., 1991. Immunology. Disease and evolution. Nature 352, 565-567.

665 Howard, J.C., Jack, R.S., 2007. Evolution of immunity and pathogens. Eur. J. Immunol. 37, 17216661723.

667 Janzen, D.H., 1980. When is it coevolution ? Evolution 34, 611-612.

668 Kim, S.M., Kang, J.H., 1997. Peroxidative activity of human Cu,Zn-superoxide dismutase. Mol. 669 Cells 7, 120-124.

670 Knudsen, G.M., Medzihradszky, K.F., Lim, K.C., Hansell, E., McKerrow, J.H., 2005. Proteomic 671 analysis of Schistosoma mansoni cercarial secretions. Mol. Cell. Proteomics 4, 1862-1875.

672 Koskella, B., Lively, C.M., 2007. Advice of the rose: experimental coevolution of a trematode 673 parasite and its snail host. Evolution 61, 152-159.

674 Little, T.J., Watt, K., Ebert, D., 2006. Parasite-host specificity: experimental studies on the basis of 675 parasite adaptation. Evolution 60, 31-38.

676 Lohse, K., Gutierrez, A., Kaltz, O., 2006. Experimental evolution of resistance in Paramecium 677 caudatum against the bacterial parasite Holospora undulata. Evolution 60, 1177-1186.

678 Loker, E.S., Adema, C.M., 1995. Schistosomes, Echinostomes and Snails: Comparative 679 Immunobiology. Parasitology today 11, 120-124.

680 Mei, H., LoVerde, P.T., 1997. Schistosoma mansoni: the developmental regulation and 681 immunolocalization of antioxidant enzymes. Exp. Parasitol. 86, 69-78.

682 Moné, Y., Gourbal, B., Duval, D., Du Pasquier, L., Kieffer-Jaquinod, S., Mitta, G., 2010a. A Large 683 Repertoire of Parasite Epitopes Matched by a Large Repertoire of Host Immune Receptors in an 684 Invertebrate Host/Parasite Model. PLoS Negl. Trop. Dis. 4, e813.

685 Moné, Y., Mitta, G., Duval, D., Gourbal, B.E., 2010b. Effect of amphotericin B on the infection success of Schistosoma mansoni in Biomphalaria glabrata. Exp. Parasitol. 125, 70-75. 
687

688

689

690

691

692

693

694

695

696

697

698

699

700

701

702

703

Morgan, A.D., Gandon, S., Buckling, A., 2005. The effect of migration on local adaptation in a coevolving host-parasite system. Nature 437, 253-256.

Mourao, M.d.M., Dinguirard, N., Franco, G.R., Yoshino, T.P., 2009a. Role of the Endogenous Antioxidant System in the Protection of Schistosoma mansoni Primary Sporocysts against Exogenous Oxidative Stress. PLoS Negl. Trop. Dis. 3, e550.

Mourao, M.M., Dinguirard, N., Franco, G.R., Yoshino, T.P., 2009b. Phenotypic screen of earlydeveloping larvae of the blood fluke, Schistosoma mansoni, using RNA interference. PLoS Negl. Trop. Dis. 3, e502.

Munoz-Antoli, C., Marin, A., Trelis, M., Toledo, R., Esteban, J.G., 2010. Sympatric and allopatric experimental infections of the planorbid snail Gyraulus chinensis with miracidia of Euparyphium albuferensis (Trematoda: Echinostomatidae). J. Helminthol., 1-5.

Nelder, J.A., Mead, R., 1965. A Simplex Method for Function Minimization. Comput. J. 7, 308313.

Nuismer, S.L., Gomulkiewicz, R., Ridenhour, B.J., 2010. When is correlation coevolution? Am. Nat. $175,525-537$.

Nuismer, S.L., Ridenhour, B.J., Oswald, B.P., 2007. Antagonistic coevolution mediated by phenotypic differences between quantitative traits. Evolution 61, 1823-1834.

Oter, O., Ribou, A.C., 2009. Quenching of long lifetime emitting fluorophores with paramagnetic molecules. J Fluoresc 19, 389-397.

Perez-Sanchez, R., Ramajo-Hernandez, A., Ramajo-Martin, V., Oleaga, A., 2006. Proteomic analysis of the tegument and excretory-secretory products of adult Schistosoma bovis worms. Proteomics 6 Supp1 1, S226-236.

Rharass, T., Vigo, J., Salmon, J.M., Ribou, A.C., 2006. Variation of 1-pyrenebutyric acid fluorescence lifetime in single living cells treated with molecules increasing or decreasing reactive oxygen species levels. Anal. Biochem. 357, 1-8. 
712 Ribou, A.C., Vigo, J., Kohen, E., Salmon, J.M., 2003. Microfluorometric study of oxygen 713 dependence of (1"-pyrene butyl)-2-rhodamine ester probe in mitochondria of living cells. J. 714 Photochem. Photobiol. B 70, 107-115.

715 Ribou, A.C., Vigo, J., Salmon, J.M., 2004. Lifetime of fluorescent pyrene butyric acid probe in 716 single living cells for measurement of oxygen fluctuation. Photochem. Photobiol. 80, 274-280.

717 Roger, E., Gourbal, B., Grunau, C., Pierce, R.J., Galinier, R., Mitta, G., 2008a. Expression analysis 718 of highly polymorphic mucin proteins (Sm PoMuc) from the parasite Schistosoma mansoni. Mol. 719 Biochem. Parasitol. 157, 217-227.

720 Roger, E., Grunau, C., Pierce, R.J., Hirai, H., Gourbal, B., Galinier, R., Emans, R., Cesari, I.M., 721 Cosseau, C., Mitta, G., 2008b. Controlled chaos of polymorphic mucins in a metazoan parasite 722 (Schistosoma mansoni) interacting with its invertebrate host (Biomphalaria glabrata). PLoS Negl. 723 Trop. Dis. 2, e330.

724 Roger, E., Mitta, G., Mone, Y., Bouchut, A., Rognon, A., Grunau, C., Boissier, J., Theron, A., 725 Gourbal, B.E., 2008c. Molecular determinants of compatibility polymorphism in the Biomphalaria 726 glabrata/Schistosoma mansoni model: New candidates identified by a global comparative 727 proteomics approach. Molecular and Biochemical Parasitology 157, 205-216.

728 Schulte, R.D., Makus, C., Hasert, B., Michiels, N.K., Schulenburg, H., 2010. Multiple reciprocal 729 adaptations and rapid genetic change upon experimental coevolution of an animal host and its 730 microbial parasite. Proceedings of the National Academy of Sciences 107, 7359-7364.

731 Selkirk, M.E., Smith, V.P., Thomas, G.R., Gounaris, K., 1998. Resistance of filarial nematode 732 parasites to oxidative stress. Int. J. Parasitol. 28, 1315-1332.

733 Shapiro, S.S., Wilk, M.B., 1965. An analysis of variance test for normality (complete samples). 734 Biometrika 52, 591-611.

735 Steinauer, M.L., 2009. The sex lives of parasites: investigating the mating system and mechanisms 736 of sexual selection of the human pathogen Schistosoma mansoni. Int. J. Parasitol. 39, 1157-1163. 
737 Stern, O., Volmer, M., 1919. The extinction period of fluorescence. Physikalische Zeitschrift 20, $738 \quad 183-188$.

739 Théron, A., Coustau, C., 2005. Are Biomphalaria snails resistant to Schistosoma mansoni? J. 740 Helminthol. 79, 187-191.

741 Théron, A., Coustau, C., Rognon, A., Gourbiere, S., Blouin, M.S., 2008. Effects of laboratory 742 culture on compatibility between snails and schistosomes. Parasitology 135, 1179-1188.

743 Théron, A., Pages, J.R., Rognon, A., 1997. Schistosoma mansoni: distribution patterns of miracidia 744 among Biomphalaria glabrata snail as related to host susceptibility and sporocyst regulatory 745 processes. Exp. Parasitol. 85, 1-9.

746 van Balkom, B.W.M., van Gestel, R.A., Brouwers, J.F.H.M., Krijgsveld, J., Tielens, A.G.M., Heck, 747 A.J.R., van Hellemond, J.J., 2005. Mass Spectrometric Analysis of the Schistosoma mansoni 748 Tegumental Sub-proteome. J. Proteome Res. 4, 958-966.

749 Van Valen, L., 1974. Molecular evolution as predicted by natural selection. Journal of Molecular 750 Evolution 3, 89-101.

751 Vermeire, J.J., Taft, A.S., Hoffmann, K.F., Fitzpatrick, J.M., Yoshino, T.P., 2006. Schistosoma 752 mansoni: DNA microarray gene expression profiling during the miracidium-to-mother sporocyst 753 transformation. Mol. Biochem. Parasitol. 147, 39-47.

754 Vermeire, J.J., Yoshino, T.P., 2007. Antioxidant gene expression and function in in vitro755 developing Schistosoma mansoni mother sporocysts: possible role in self-protection. Parasitology $756 \quad 134,1369-1378$.

757 Webster, J.P., Davies, C.M., 2001. Coevolution and compatibility in the snail-schistosome system. 758 Parasitology 123 Suppl, S41-56.

759 Webster, J.P., Gower, C.M., Blair, L., 2004. Do hosts and parasites coevolve? Empirical support 760 from the Schistosoma system. Am. Nat. 164 Suppl 5, S33-51. 
761 Wu, X.J., Sabat, G., Brown, J.F., Zhang, M., Taft, A., Peterson, N., Harms, A., Yoshino, T.P., 2009.

762 Proteomic analysis of Schistosoma mansoni proteins released during in vitro miracidium-to763 sporocyst transformation. Mol. Biochem. Parasitol. 164, 32-44.

764 Yim, M.B., Chock, P.B., Stadtman, E.R., 1993. Enzyme function of copper, zinc superoxide 765 dismutase as a free radical generator. J. Biol. Chem. 268, 4099-4105.

766 Yim, M.B., Kang, J.H., Yim, H.S., Kwak, H.S., Chock, P.B., Stadtman, E.R., 1996. A gain-of767 function of an amyotrophic lateral sclerosis-associated $\mathrm{Cu}, \mathrm{Zn}$-superoxide dismutase mutant: An 768 enhancement of free radical formation due to a decrease in $\mathrm{Km}$ for hydrogen peroxide. Proc. Natl. 769 Acad. Sci. U. S. A. 93, 5709-5714.

770 Yoder, J.B., Nuismer, S.L., 2010. When does coevolution promote diversification? Am. Nat. 176, $771 \quad 802-817$.

772 Zelck, U.E., Von Janowsky, B., 2004. Antioxidant enzymes in intramolluscan Schistosoma mansoni 773 and ROS-induced changes in expression. Parasitology 128, 493-501. 


\section{Figure legends}

777

778

779

Fig. 1. Effect of hydrogen peroxide $\left(\mathrm{H}_{2} \mathrm{O}_{2}\right)$ on Schistosoma mansoni sporocysts. (A) Cytotoxicity among S. mansoni sporocysts $2 \mathrm{~h}$ after exposure to different $\mathrm{H}_{2} \mathrm{O}_{2}$ concentrations. The asterisk indicates a significant difference $(P<0.05)$ in the cytotoxic effect of $\mathrm{H}_{2} \mathrm{O}_{2}$ on $S$. mansoni Guadeloupean strain (SmGH2) versus S. mansoni Brazilian strain (SmBRE) sporocysts. (B) Percent sporocyst mortality after $4 \mathrm{~h}$ exposure to different $\mathrm{H}_{2} \mathrm{O}_{2}$ concentrations. The asterisk indicates a significant difference $(P<0.05)$ in the mortality rates of SmGH2 versus SmBRE sporocysts.

Fig. 2. Constitutive total antioxidant capacities of Schistosoma mansoni Guadeloupean strain (SmGH2) and S. mansoni Brazilian strain (SmBRE) sporocysts. Values are expressed as $\mu \mathrm{M}$ of antioxidant activity per $10 \mu \mathrm{g}$ of sporocyst proteins. The asterisk indicates a significant difference $(P<0.05)$.

Fig. 3. Ratios of $\mathrm{Zn}-\mathrm{Cu}$ superoxide dismutase (Zn-Cu SOD, Smp_176200.2) transcript levels in the two strains of Schistosoma mansoni miracidia (Guadeloupean strain, SmGH2 and Brazilian strain, SmBRE). Ratios were determined using real-time quantitative PCR and are expressed relative to the expression levels of $28 \mathrm{~s}$ rRNA and $\alpha$-tubulin. The histogram represents the average values of duplicates \pm S.D. The expression ratio was calculated according to the formula: $\mathrm{R}=2(\Delta \mathrm{Ct})$, where $\Delta \mathrm{Ct}$ represents $\mathrm{Ct}$ (target gene) $-\mathrm{Ct}$ (constitutively expressed gene). 
Fig. 4. Intracellular ROS measurements in single Biomphalaria glabrata hemocytes (A) Global reactive oxygen species (ROS) concentration in each snail strain. The histogram represents the ROS concentrations in arbitrary units (-fold mean) for the Biomphalaria glabrata Guadeloupean strain, BgGUA and Brazilian strain, BgBRE. The asterisk indicates a significant difference $(P<0.05)$ in ROS production by hemocytes of the two snail strains. (B) ROS concentrations in hemocyte populations from BgGUA and BgBRE snails. The histograms represent the fluorescent lifetimes of 1-pyrenebutyric acid (PBA)-loaded hemocytes from eight each of BgGUA and BgBRE; 108 single hemocytes from eight $\mathrm{BgBRE}$ and 111 hemocytes from eight individuals of BgGUA snails were assessed. The $x$ axis represents the fluorescent lifetime in nanoseconds, while the $y$ axis corresponds to the number of cells.

Fig. 5. Hydrogen peroxide $\left(\mathrm{H}_{2} \mathrm{O}_{2}\right)$ production by Biomphalaria glabrata hemocytes. Cumulative production of $\mathrm{H}_{2} \mathrm{O}_{2}$ was measured using Amplex Red. The data are presented as the mean ( \pm S.D.) of Amplex Red absorbance at $570 \mathrm{~nm}\left(\mathrm{~A}_{570 \mathrm{~nm}}\right)$ per 45,000 cells over five replicates. The asterisk indicates a significant difference $(P<0.05)$ in $\mathrm{H}_{2} \mathrm{O}_{2}$ production from hemocytes of B. glabrata Guadeloupean strain, BgGUA, versus Brazilian strain, BgBRE.

Fig. 6. Constitutive superoxide anion plasma content in Biomphalaria glabrata Guadeloupean strain, BgGUA, versus Brazilian strain, BgBRE. The superoxide anion plasma content was assessed by spectrophotometric measurement $(620 \mathrm{~nm})$ of nitroblue tetrazolium (NBT) reduction. At $3 \mathrm{~h}$ after initiation of the reaction, the BgBRE plasma contained significantly more superoxide anion than that from $\mathrm{BgGUA}$ (the asterisk indicates a significant difference; $P<0.05)$. 
827 Fig. 7. Infection rates and intensities in sympatric and allopatric Schistosoma mansoni/Biomphalaria glabrata combinations. The percentage of snails infected and the intensity of infection: number of mother sporocysts (SpI) developed ( $n \mathrm{SpI}$ ) was measured after individual snails were challenged with different miracidial doses $(1,10,20,30$ or 50 miracidia (Mi)).

833 Fig. 8. Schematic representation of our reactive oxygen species (ROS)-based co-evolutionary hypothesis. The percentage of prevalence is indicated for each Biomphalaria glabrata/Schistosoma mansoni combination. The number of arrows represents the differential host oxidant (ROS) or parasite antioxidant (ROS scavenger) capabilities. Biomphalaria glabrata Brazilian strain, BgBRE, and Guadeloupean strain, BgGUA; S. mansoni Brazilian strain, SmBRE, and Guadeloupean strain, SmGH2. 
Table 1

Primer sequences for Reverse Transcription-quantitative PCR in this study.

\begin{tabular}{llll}
\hline Gene Name and SchistoDB ID & Amplicon Length & Smp_scaffold & Forward primer (5’ to 3') \\
\hline Glyceraldehyde-3-phosphate dehydrogenase (GAPDH) Smp_056970 & 125 & 000155 & TGGCCGTGGAGCGATGCAAA \\
Glutathione S-transferase omega Smp_152710 & 148 & 000154 & ACAGCTCTAGTTGTCGACCAAAC) \\
Glutathione S-transferase 28 kD (GST 28) Smp_054160 & 128 & 000143 & CGGACGCGGACGTGCTGAAT \\
Glutathione-S-transferase 26 kD (GST 26) Smp_163610 & 104 & 000249 & GCAAAGCTGGTGGTTTGGGGC \\
Glyoxalase II Smp_091010 & 124 & 000428 & ATGGCCTTCATTGCTTTGGACAGA \\
Thioredoxin peroxidase (TPX) Smp_158110 & 101 & 100 & CAAAGGCCTTGTACAACCAACTCC \\
Superoxide dismutase (SOD) Smp_176200.2 & & 000615 & AGTGGACTCAAGGCTG \\
\hline
\end{tabular}

Gene names are given according to the SchistoDB accession numbers (http://schistodb.net/schistodb20/). Their respective scaffolds are included in the table. Smp_163610 primer sequences are given according to the mRNA sequence of the gene (XM_002582157.1) due to inconsistency in the genome assembly. $\alpha$-tubulin and 28S primers sequences were previously published (Bahia et al., 2006; Roger et al., 2008a). 
A

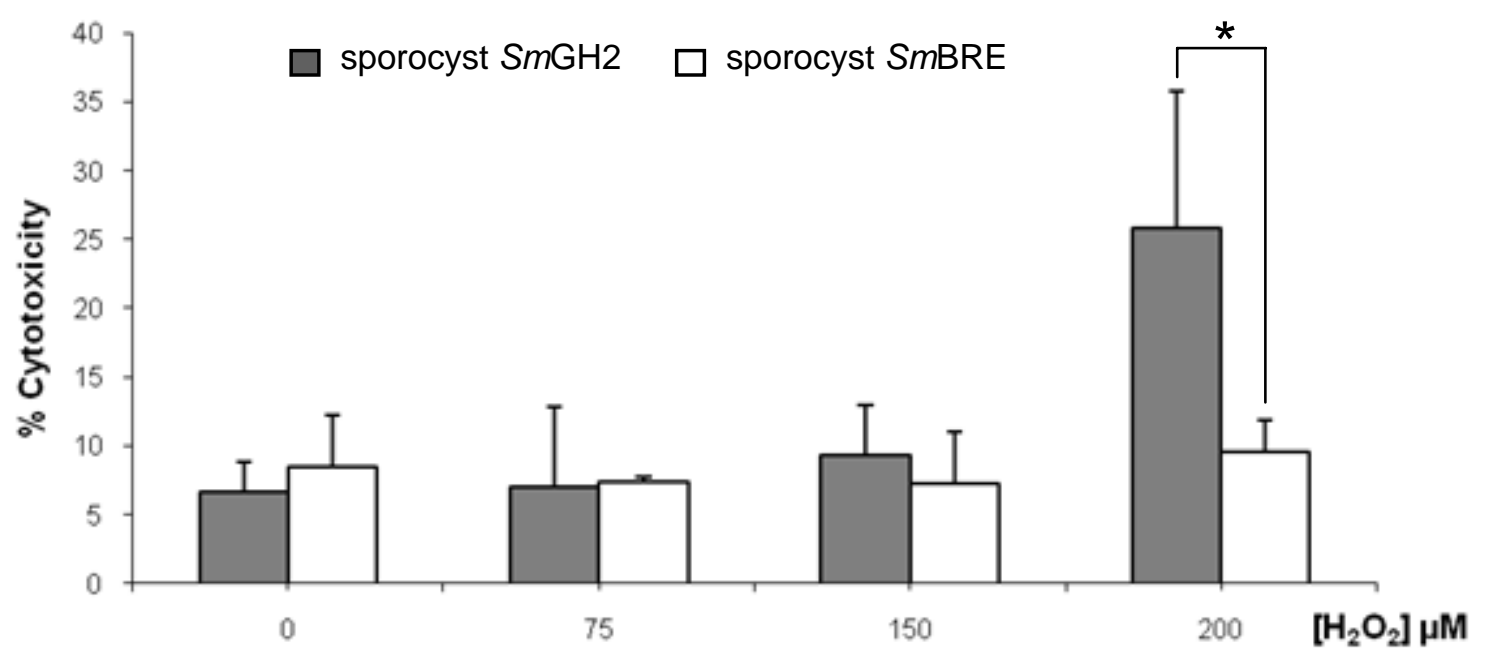

B



$\left[\mathrm{H}_{2} \mathrm{O}_{2}\right] \mu \mathrm{M}$ 
sporocyst SmGH2 $\square$ sporocyst SmBRE

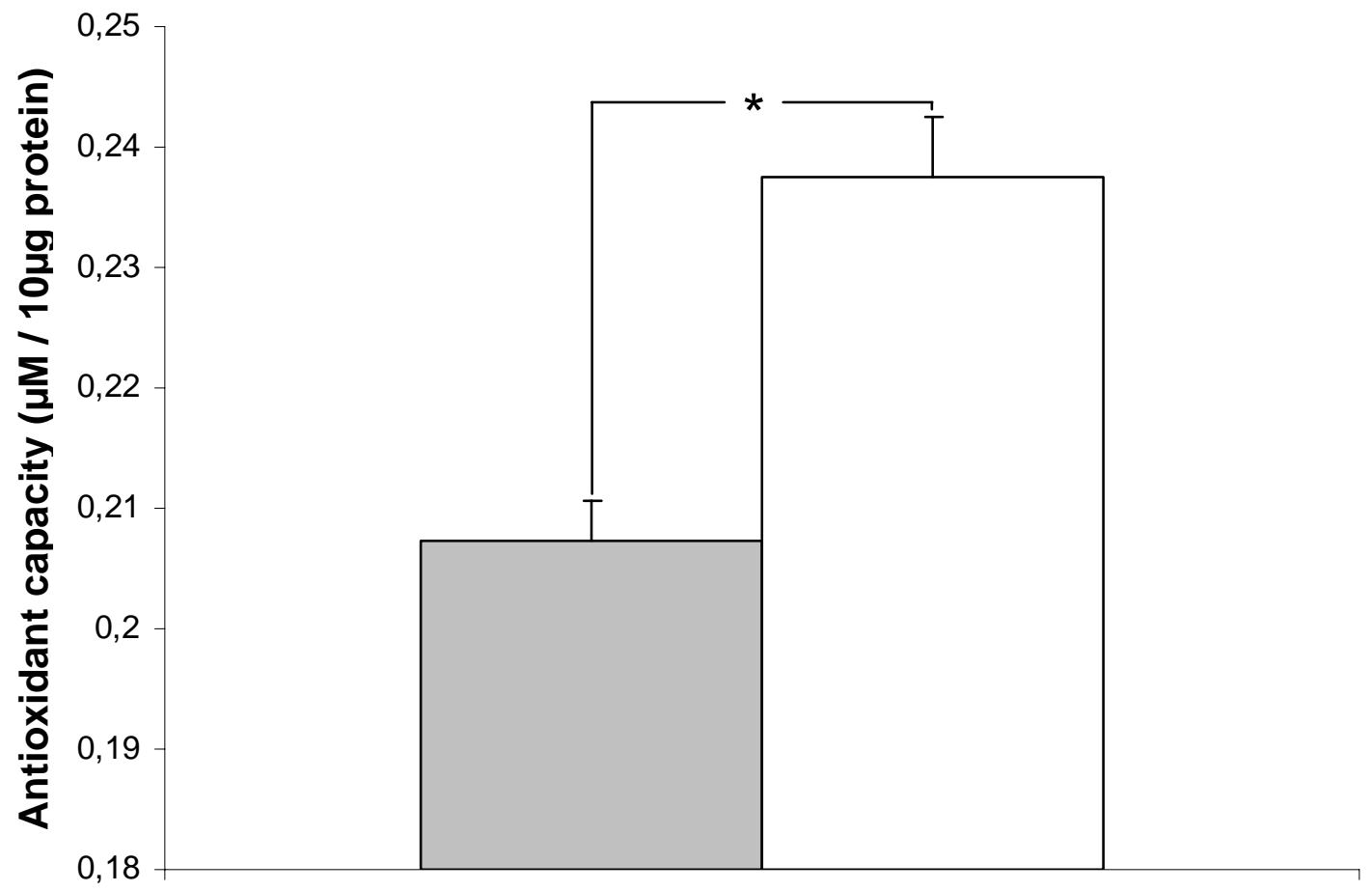







A

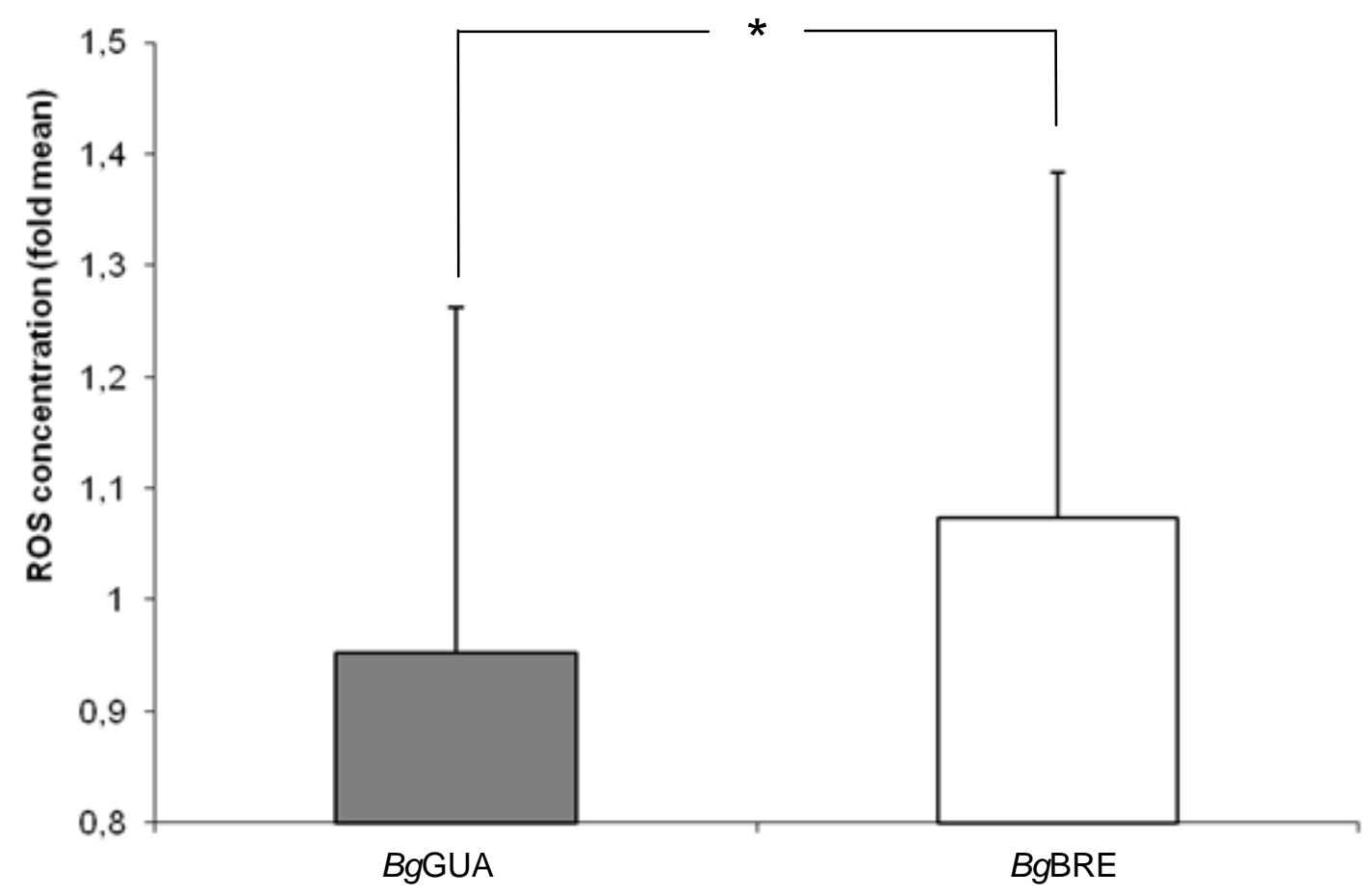

B






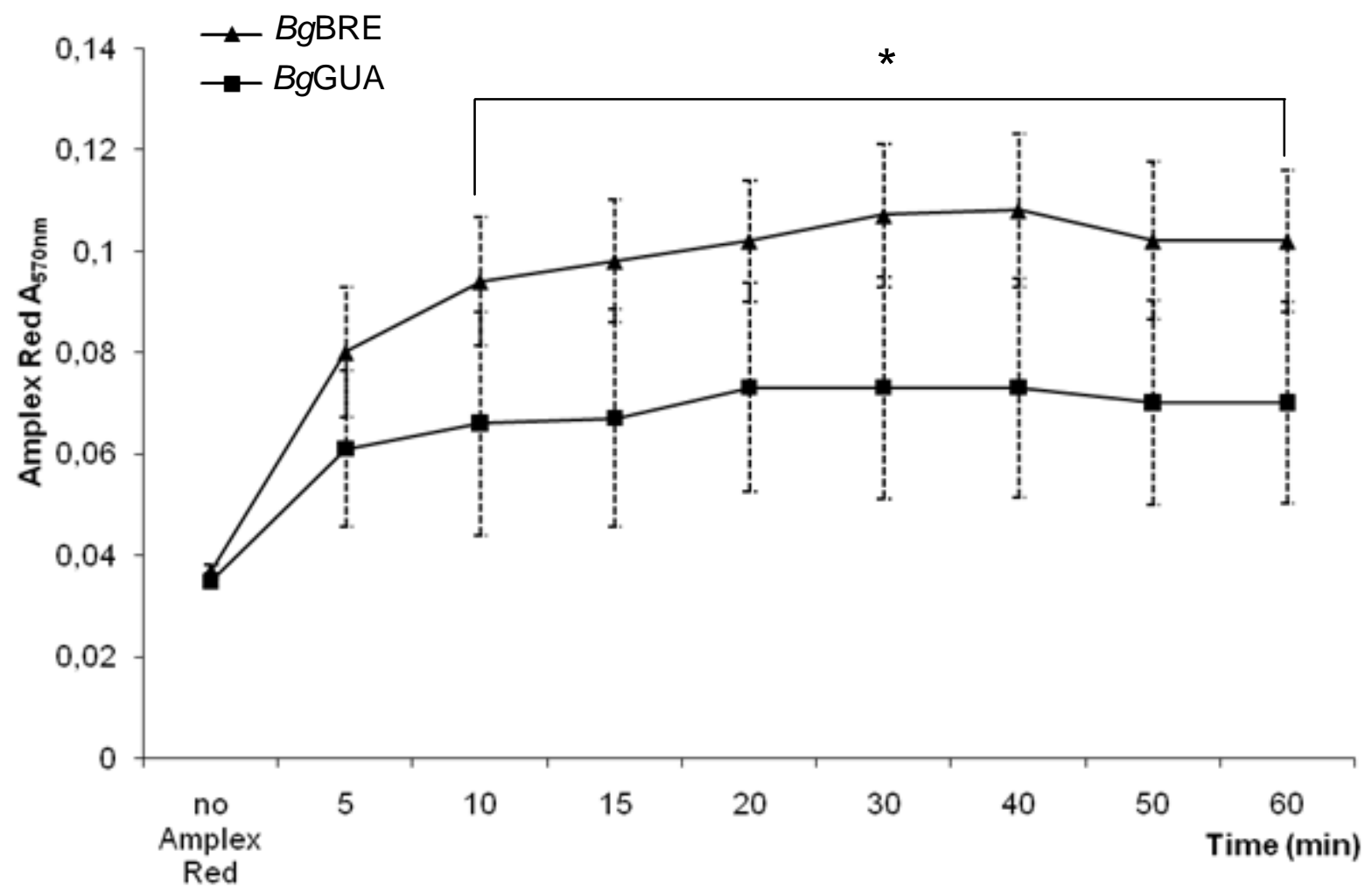




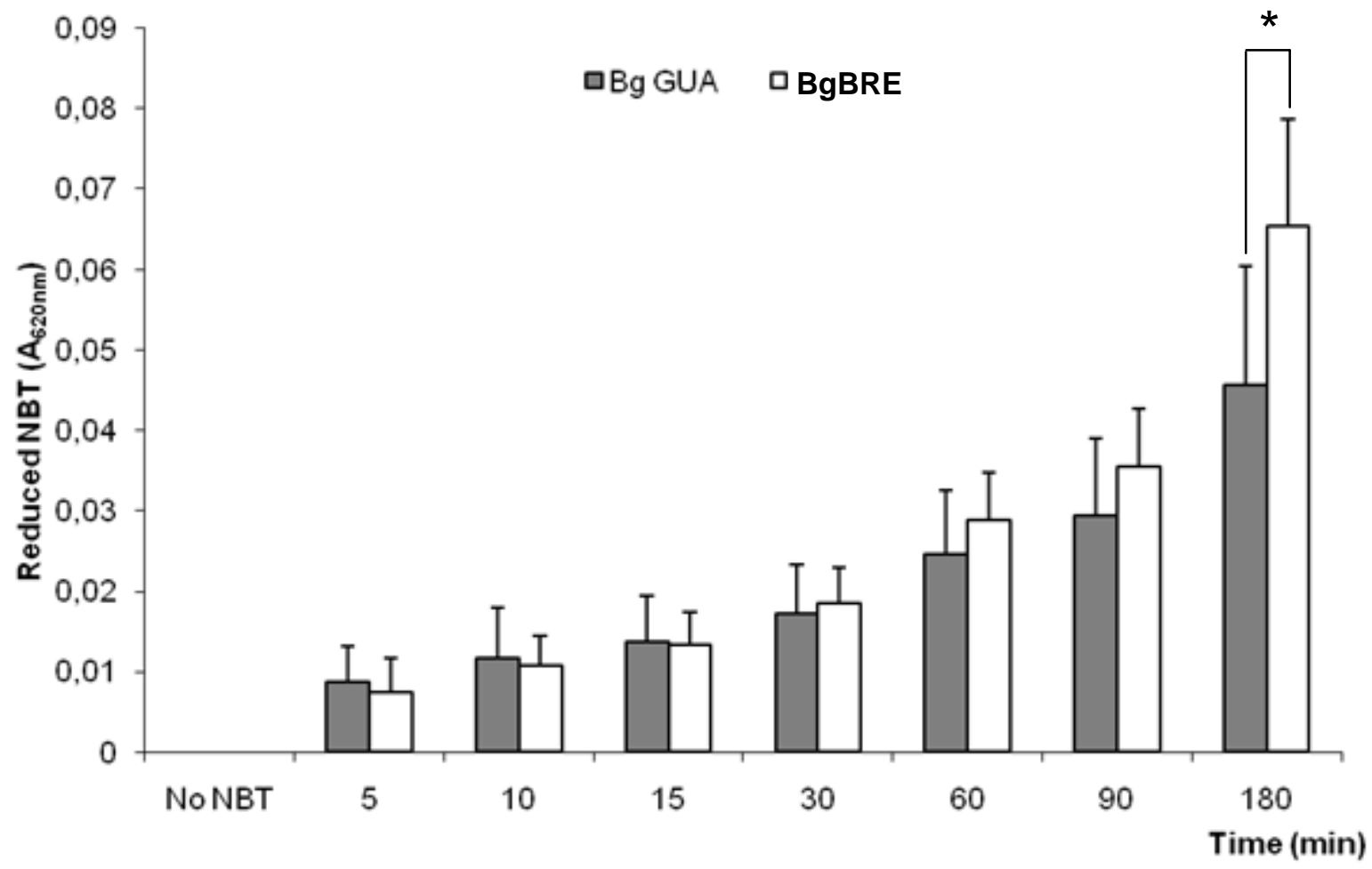



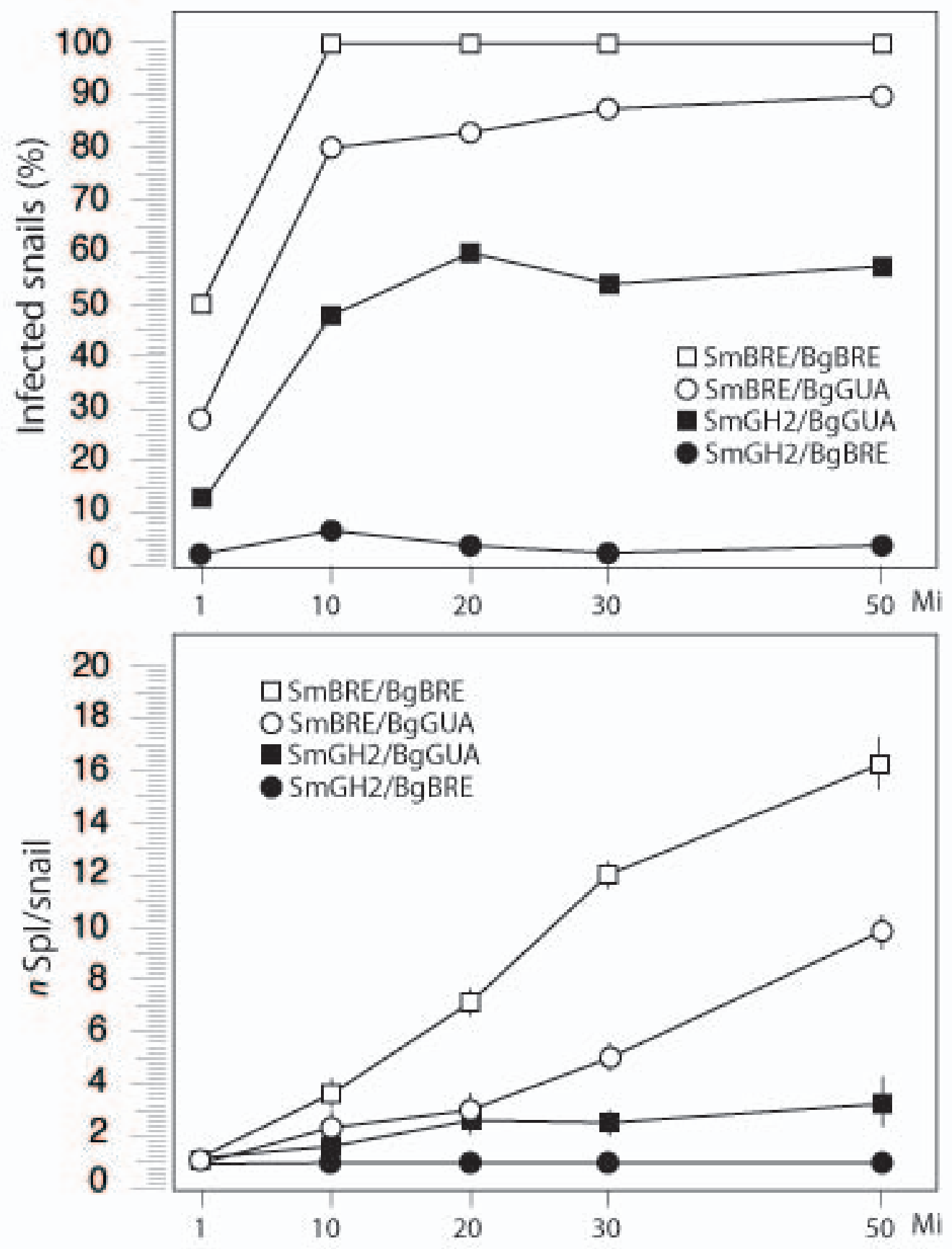
BgBRE

BgGUA



SmBRE

SmGH2 